\title{
TISSUE DISTRIBUTION OF I'181 LABELED HUMAN SERUM ALBUMIN FOLLOWING INTRAVENOUS ADMINISTRATION
}

\author{
By MARCUS A. ROTHSCHILD,1 ARTHUR BAUMAN, ${ }^{2}$ ROSALYN S. YALOW, AND \\ SOLOMON A. BERSON \\ (From the Radioisotope Service, Veterans Administration Hospital, Bronx, N. Y.)
}

(Submitted for publication March 14, 1955; accepted April 27, 1955)

Previous studies utilizing $I^{\mathbf{1 3 1}}$ labeled human serum albumin have revealed that approximately 60 per cent of the total exchangeable albumin of nonedematous subjects is in extravascular locations $(1,2)$. Following intravenous administration, approximately 4 to 7 days are required for essentially complete equilibration of the labeled albumin between plasma and extravascular tissues $(2,3)$. In almost all cases the plasma disappearance curves, appropriately corrected for metabolic degradation, manifest two major components with half times of approximately 3 to 5 hours and 24 to 30 hours, respectively, suggesting that there are at least two groups of albumin containing extravascular compartments which equilibrate with plasma at different rates $(2,3)$. However, the distribution of extravascular albumin and the anatomical sites of the rapidly and slowly equilibrating extravascular compartments have not yet been quantitatively defined although previous studies utilizing massive doses of heterologous serum proteins in rabbits established the presence of these proteins in the extravascular phase of muscle 48 hours after intravenous administration (4).

During the course of recent investigations on the fate of $I^{131}$ labeled human serum albumin in heart failure (3), the deaths of two subjects, 1 and 22 days, respectively, following the intravenous administration of the labeled albumin, offered the opportunity for post mortem analysis of radioactivity in the various tissues. The times of death were such that comparison between the two cases yielded suggestive information regarding the distribution of iodoalbumin and the sites of the slowly and rapidly equilibrating extravascular compartments. Further observations were then made on skin and muscle tissue removed during surgical operations.

1 Dazian Foundation Fellow.

2 National Heart Institute Research Fellow.

\section{METHODS}

The subjects were hospitalized male patients on the Medical and Surgical Services of the Veterans Administration Hospital, Bronx, N. Y.

Patient V. P. had arteriosclerotic heart disease and congestive heart failure and died suddenly with a myocardial infarction 24 hours after the intravenous administration of $112 \mu \mathrm{c}$ of $\mathrm{I}^{1 \mathrm{si}}$ labeled human serum albumin. Patient A. M. had rheumatic heart disease, aortic insufficiency, congestive heart failure and persistent proteinuria and expired in pulmonary edema 22 days after receiving $107 \mu \mathrm{c}$ of labeled albumin. In the interval between administration of the tracer protein and the deaths of the patients, serial blood samples were taken and complete urinary collections were made. Ten drops of Lugol's solution were administered daily to inhibit the uptake of free iodide by the thyroid. The plasma concentration curves of $I^{181}$ tagged albumin which were obtained during life were extrapolated to the time of death in each patient. In each case post mortem examination was performed 24 hours after death at which time the tissues were obtained for analysis.

Five specimens of muscle and three specimens of skin were obtained during surgical procedures from five patients fifteen to twenty minutes after the intravenous administration of $\mathrm{I}^{131}$ labeled albumin. In addition, ten muscle specimens and eight skin specimens were obtained from twelve patients one to eleven days after administration of $\mathrm{I}^{182}$ labeled albumin. Plasma samples were obtained simultaneously with all surgical tissue specimens which were taken primarily from the thoracic and abdominal walls.

Representative samples of all tissues were trimmed of large blood vessels, patted free of excess blood, placed into Kimbal screw top culture tubes, and weighed. Care was taken to strip all subcutaneous tissue from skin samples. The tissues were then assayed for radioactivity in a well-type scintillation counter with a sensitivity of $1.00 \times 10^{\circ}$ cts. per min. per $\mu_{\mathrm{C} \mathrm{I}} \mathrm{I}^{121}$.

The small vessel plasma contents of muscle and skin were determined from the total radioactivities of these tissues relative to those of plasma 15 to 20 minutes after the intravenous administration of $\mathrm{I}^{121}$ labeled albumin. It was assumed that negligible quantities of the labeled protein had passed into the extravascular spaces at this time. The small vessel plasma contents of other tissues were taken from the values given by Gibson, Peacock, Seligman, and Sack (5). The albumin- $\mathrm{I}^{121}$ contents of 
"bloodless" tissues at later times were then estimated by applying these corrections for plasma content to the observed total tissue radioactivities.

Serum albumin concentrations were determined according to the method of Kingsley (6).

\section{RESULTS}

$A-P o s t$ mortem tissue examinations in subjects $V$. P. and $A . M$.

Patient V. P. expired only 24 hours following the administration of the tracer protein and therefore distribution was presumed to be incomplete in the slowly equilibrating extravascular compartments. At the time of death 40 per cent of the iodoalbumin had left the blood stream. In patient A. M., distribution was complete at the time of death (22 days following administration of albumin- $\mathrm{I}^{131}$, and specific activities of pleural fluid and plasma were found to be identical $(0.00150$ per cent of administered albumin-I ${ }^{181}$ per gram of albumin). Sixty per cent of the total exchangeable albumin was located extravascularly.

The results of the radioactive tissue assays are presented in Table I. With the exception of dura mater in subject A. M., no organ in either patient had a higher concentration of radioactivity than the plasma. The thyroid and gastric glands in subject A. M. might have shown a higher concentration of radioactivity if the administration of Lugol's solution had not reduced their capacity to concentrate radioiodide released from the degraded protein. The extremely high relative activity of the dura mater in subject A. M. was probably due to contamination from an external source.

The strikingly low concentration of iodoalbumin in the livers of both patients is of particular interest. The extravascular exchangeable albumin content of the entire liver was equivalent to the albumin contained in $77 \mathrm{ml}$. of plasma and $39 \mathrm{ml}$. of plasma in patients V.P. and A. M., respectively. Including blood content, exchangeable albumin

TABLE I

Tissue distribution of $I^{181}$ labeled albumin

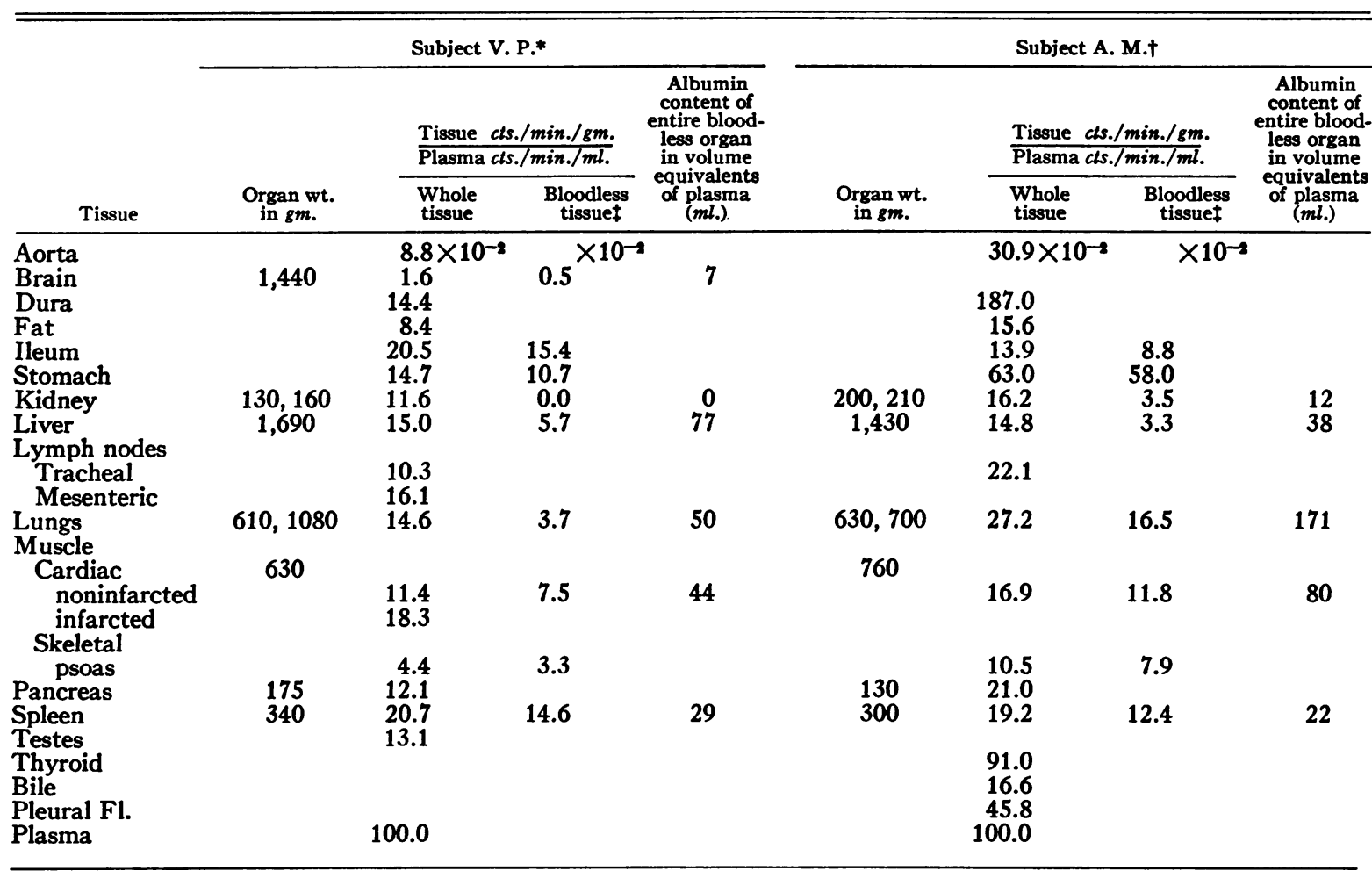

* Pt. V. P. expired 24 hours following intravenous administration of $I^{131}$ labeled human serum albumin. $\dagger$ Pt. A. M. expired 22 days following intravenous administration of $I^{131}$ labeled human serum albumin. ¥ Whole tissue counts corrected for plasma content of tissue as described under Methods. 
TABLE II

Small vessel plasma volumes of skin and muscle (per cent by weight of whole tissue)*.

\begin{tabular}{|c|c|c|}
\hline Subject & Skin & Muscle \\
\hline $\begin{array}{l}\text { N. D. } \\
\text { V. C. } \\
\text { H. M. } \\
\text { J. A. } \\
\text { A. F. }\end{array}$ & $\begin{array}{l}1.2 \\
2.8 \\
1.0\end{array}$ & $\begin{array}{l}2.7 \\
2.9 \\
2.2 \\
2.9 \\
2.7\end{array}$ \\
\hline & 1.9 & 2.7 \\
\hline
\end{tabular}

* Based on relative tissue/plasma radioactivities 15 to 20 minutes after intravenous administration of $I^{181}$ labeled albumin.

present in the livers of these subjects was less than 10 grams or at most, 3 to 4 per cent of the total exchangeable albumin in the body.

Liver, spleen, and small intestine failed to show any increase in concentration of iodoalbumin relative to that of plasma between 1 and 22 days. The other viscera showed varying increments, but the total iodoalbumin content of these organs was only a small fraction of the total exchangeable albumin, even when the blood content is included.

Both skeletal muscle and noninfarcted cardiac muscle revealed a definite increase in "bloodless" tissue radioactivity between the 1 st and 22 nd days. However, since both patients were in heart failure at the time of death, it was not possible to establish values for edema free muscle other than to note that the maximum value was not greater than about 10 per cent that of plasma. The higher concentration of radioactivity in the infarcted cardiac muscle is explained by the seepage of blood into the infarcted area.

\section{$B-M$ uscle and skin samples obtained at operation}

The mean plasma volumes of muscle and skin as determined from tissues obtained 15 to $20 \mathrm{~min}$ - utes after $\mathrm{I}^{131}$ albumin administration were 2.7 per cent and 1.9 per cent, by weight, respectively (Table II). Eighteen to 24 hours later "bloodless" muscle had a concentration of only 0.6 per cent that of the plasma but this value rose gradually over the next four to five days to 3.5 per cent after which no further increase occurred (Figure 1). "Bloodless" skin, however, showed a more rapid initial increase, reaching a concentration of 11.0 per cent relative to the plasma at eighteen hours and this was followed by a further gradual rise to 25 to 30 per cent by the end of 5 to 7 days (Figure 1 ).

\section{DISCUSSION}

Since the specific activity of labeled albumin in accessible extravascular compartments such as ascitic fluid (7) and pleural fluid (present studies) eventually becomes virtually equal to that in plasma, it seems reasonable to conclude that albumin- $\mathrm{I}^{131}$ is distributed elsewhere in the same manner as endogenous serum albumin, whatever reservations may yet remain $(2,3)$ regarding the relative rates of metabolism of endogenous albumin and albumin- ${ }^{131}$. Therefore, in the discussion below, it is assumed that the distribution of albumin- $\mathrm{I}^{131}$ reflects that of endogenous serum albumin.

\section{Albumin in viscera}

Since radioiodide is excreted rapidly following its liberation from degraded protein (2), the concentration of radioactivity in tissues, under the conditions of these studies, may be regarded as due almost entirely to protein. In all tissues except thyroid and stomach $^{\mathbf{3}}$ (which selectively

${ }^{3}$ Iodine concentrations in these organs was partially inhibited by the administration of Lugol's solution.

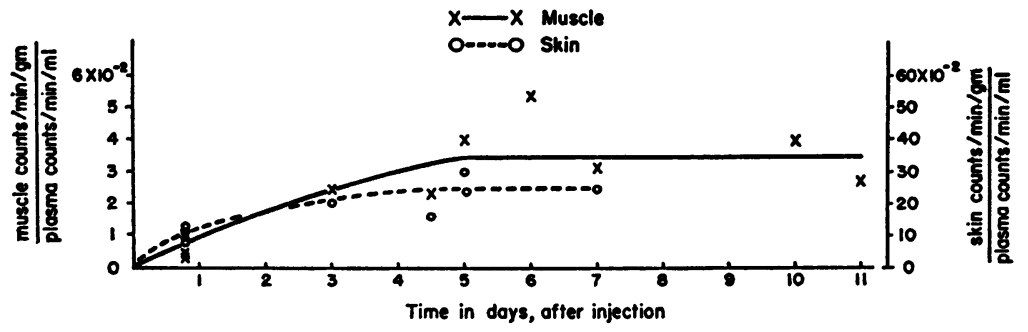

Fig. 1. Equilibration of the Albumin of Muscle and Skin with Plasma Albumin

Tissue counts have been corrected for plasma content. 
conicentrate iodine) nonprotein-bound radioiodine contributes an insignificant contamination as in plasma where 98 per cent or more of the radioactivity can be shown to be albumin- $\mathrm{I}^{181}(2)$. However, pathologic conditions were probably responsible for higher than normal concentrations of albumin- $\mathrm{I}^{131}$ in some tissues of the subjects studied here at autopsy. The concentration of radioactivity in the lungs of patient $\mathrm{A}$. M. was probably elevated by the presence of vascular congestion and pulmonary edema whereas the correction for plasma content was based on normal lung tissue. Also, patient A. M. had considerable proteinuria ( 3 to $5 \mathrm{gm}$. per day) and at least some of the albumin-I ${ }^{181}$ in his "bloodless" kidney tissue may have been due to protein in the renal collecting system rather than in the interstitium. Therefore, the total exchangeable albumin content of normal viscera may be even lower than that observed here. In subject A. M. the total extravascular albumin content of heart, liver, spleen, kidneys, and lungs amounted to about one-tenth of the circulating plasma content.

In view of the low hydrostatic pressure existing in the portal venous system relative to the plasma oncotic pressure, it has been suggested on theoretical grounds that the extracellular fluids of the liver must maintain a high protein concentration in order to resist desiccation (8). Although in vivo studies in the human subject (2), in the dog (5) and in the rabbit (9), have failed to demonstrate significant hepatic extraction of I $^{181}$ labeled albumin from the first circulation (9) to the first hour $(2,5)$ following its administration, the possibility of hepatic concentration at later intervals had not been investigated. The observations presented here indicate that even after 22 days there is no appreciable quantity of exchangeable albumin in the extravascular spaces of the liver and hence the volume of the extracellular space of the liver must be small. This is confirmed by the lack of histologic evidence for a significant interstitial space in hepatic parenchyma.

\section{Albumin in skin and muscle}

The concentration of exchangeable albumin in whole skin exclusive of its blood vessel content is about 25 to 30 per cent that in plasma. If the serum albumin of skin is located solely in the in-
TABLE III

Major sites of albumin distribution

\begin{tabular}{lc}
\hline & $\begin{array}{c}\text { Per cent of total } \\
\text { exchangeable } \\
\text { albumin }\end{array}$ \\
\hline Plasma & 40 \\
Skin & 18 \\
Muscle & 15 \\
Heart, lungs, liver, kidney, spleen & $\frac{4}{77}$ \\
Total accounted for in above sites & $\mathbf{7 7}$ \\
\hline
\end{tabular}

terstitial fluid, estimated at 60 per cent of skin weight (10), then the concentration in this fluid is about 45 per cent that in plasma or normally about 2.0 grams per $100 \mathrm{ml}$. Estimates of total skin mass vary greatly but the most reasonable values appear to be about 6 to 7 per cent of body weight $(11,12)$. Since the plasma volume is about 4 per cent of body weight (13) and contains about 40 per cent of the total exchangeable albumin in the body, the total albumin content of skin accounts for about 18 per cent of the total exchangeable albumin. The high albumin concentration in whole skin is undoubtedly related to the large volume of extracellular fluid in this tissue and may explain the relatively large quantity of extravascular albumin observed in a myxedematous subject reported elsewhere (3).

The concentration of exchangeable albumin in extravascular compartments of muscle is only 3.5 per cent that in plasma, but since muscle constitutes 40 to 45 per cent of body weight $(11,14)$, this tissue accounts for about 15 per cent of the total exchangeable albumin. Assuming that all the albumin of muscle is located in the interstitial fluid estimated at 10 per cent (15) to 16 per cent (16) of muscle, its concentration in this fluid is then approximately 35 per cent to 21 per cent of the plasma concentration or normally about 1.5 grams to 0.92 gram per $100 \mathrm{ml}$, respectively.

Table III summarizes the data pertaining to the major sites of albumin distribution. Almost four-fifths of the total exchangeable albumin can be accounted for in plasma, skin, muscle and the thoracic and abdominal viscera listed. The remainder must include that present in other viscera, subcutaneous tissue, fat, lymphatic trunks. and bone marrow. Mixing of intravenously administered iodoalbumin with the extravascular albumin pools of muscle, certain viscera, and at least an ap- 
preciable portion of skin, requires 4 to 5 days for complete equilibration. These observations are in agreement with the half times of disappearance following direct injection of albumin- ${ }^{131}$ into skin and muscle (2). Other viscera, such as liver and spleen, and possibly some compartment of skin have albumin pools which appear to equilibrate with plasma albumin within a day or less. It must be emphasized that the half times of the 2 compartments of distribution observed in the plasma disappearance curves previously described (2) and discussed above are not the half times for equilibration of the 2 groups of extravascular compartments brought to light by the characteristics of the plasma concentration curves. The latter half times cannot be calculated from the plasma disappearance curves alone (7).

\section{SUMMARY AND CONCLUSIONS}

1. Tissue radioactivities were determined at autopsy in two patients who died 1 and 22 days following the intravenous administration of $I^{131}$ labeled albumin and in surgical specimens of skin and muscle obtained from human subjects 15 minutes to 11 days following iodoalbumin administration.

2. Plasma and the extravascular spaces of skin, muscle and the large thoracic and abdominal viscera account for 75 to 80 per cent of the total exchangeable albumin. Skin and muscle contain one-half of the total extravascular albumin. The extravascular space of the liver contains less than 1 per cent of the body's total exchangeable albumin.

3. Four to 5 days are required for essentially complete equilibration of the extravascular exchangeable albumin pools of skin and muscle with plasma albumin.

\section{ACKNOWLEDGMENTS}

We wish to express our appreciation to Dr. Harold Stein, Dr. S. Donald Malton, Dr. Frederick M. Mitchell, and Dr. Robert W. Delaplaine of the Surgical Service of the Veterans Administration Hospital, Bronx, New York, for their cooperation in obtaining the surgical specimens. We are also indebted to Mrs. Frieda Steiner and Miss Eve Spelke for their secretarial assistance, to Mr. Paul Newman for the illustration and to Mr. Carl Bacot for technical assistance.

\section{REFERENCES}

1. Sterling, $\mathrm{K}$., The turnover rate of serum albumin in man as measured by $\mathrm{I}^{131}$-tagged albumin. J. Clin. Invest., 1951, 30, 1228.

2. Berson, S. A., Yalow, R. S., Schreiber, S. S., and Post, J., Tracer experiments with $\mathrm{I}^{181}$ labeled human serum albumin: distribution and degradation studies. J. Clin. Invest., 1953, 32, 746.

3. Bauman, A., Rothschild, M. A., Yalow, R. S., and Berson, S. A., Distribution and metabolism of $\mathrm{I}^{12 \mathrm{n}}$ labeled human serum albumin in congestive heart failure with and without proteinuria. J. Clin. Invest., 1955, 34, 1359.

4. Gitlin, D., and Janeway, C. A., Studies on the plasma proteins in the interstitial fluid of muscle. Science, 1954, 120, 461.

5. Gibson, J. G., 2nd, Peacock, W. C., Seligman, A. M., and Sack, T., Circulating red cell volume measured simultaneously by the radioactive iron and dye methods. J. Clin. Invest., 1946, 25, 838.

6. Kingsley, G. R., A rapid method for the separation of serum albumin and globulin. J. Biol. Chem., 1940, 133, 731.

7. Berson, S. A., and Yalow, R. S., The distribution of $I^{12}$ labeled human serum albumin introduced into ascitic fluid: Analysis of the kinetics of a three compartment catenary transfer system in man and speculations on possible sites of degradation. J. Clin. Invest., 1954, 33, 377.

8. Starling, E. H., Mercer's Company Lectures on the Fluids of the Body. London, A. Constable and Co., Ltd., 1909.

9. Schreiber, S. S., Bauman, A., Yalow, R. S., and Berson, S. A., Blood volume alterations in congestive heart failure. J. Clin. Invest., 1954, 33, 578.

10. Flemister, L. J., Distribution of available water in the animal body. Am. J. Physiol., 1942, 135, 430.

11. Shohl, A. T., Mineral Metabolism. Am. Chem. Soc. Monograph. Series No. 82, New York, Reinhold Pub. Co., 1939.

12. Leider, M., and Buncke, C. M., Physical dimensions of the skin. Arch. Dermat. \& Syph., 1954, 69, 563.

13. Berson, S. A., Blood volume in health and disease. Bull. New York Acad. Med., 1954, 30, 750.

14. Patten, B. M., Human Embryology. Phila., The Blakiston Co., 1946.

15. Mokotoff, R., Ross, G., and Leiter, L., The electrolyte content of skeletal muscle in congestive heart failure: a comparison of results with inulin and chloride as reference standards for extracellular water. J. Clin. Invest., 1952, 31, 291.

16. Harrison, H. E., Darrow, D. C., and Yannet, H., The total electrolyte content of animals and its probable relation to the distribution of body water. J. Biol. Chem., 1936, 113, 515. 